\title{
ПРАВО
}

LAW

Научная статья

УДК 341-048.87(4/5)

https://doi.org/10.24866/1813-3274/2021-3/111-123

\section{ИДЕЯ ВСЕОБЪЕМЛЮЩЕГО (БОЛЬШОГО) ЕВРАЗИЙСКОГО ПАРТНЁРСТВА В СВЕТЕ МЕЖДУНАРОДНОГО ПРАВА (ЧасТЬ 2)}

\section{В. М. Шумилов ${ }^{1}$}

Всероссийская академия внешней торговли Министерства экономического развития Российской Федерации, г. Москва, Россия

E-mail: mezhdekpravo@gmail.com

\section{М. Р. Салия ${ }^{2}$}

Всероссийская академия внешней торговли Министерства экономического развития Российской Федерации, г. Москва, Россия

E-mail: salimarianna@yandex.ru

Аннотация. Суть идеи «Всеобъемлющего евразийского партнёрства», озвученной в 2016 году, - усилить интеграционное взаимодействие между Евразийским экономическим союзом (ЕАЭС) и государствами Азиатско-Тихоокеанского региона (ATP), соответствующими международными организациями и прочими интеграционными объединениями в регионе. В итоге должна быть создана региональная зона свободной торговли и свободная инвестиционная зона с участием ЕАЭС и государств-членов ЕАЭС. Главным нормативным регулятором этого процесса выступают международные договоры и мягкое право, и сама направленность такой интеграции объясняется созревшим международным правосознанием и происходящей перестройкой современного международного правопорядка. В статье раскрывается, какими практическими действиями и с каким нормативным инструментарием ЕАЭС идёт к Большому евразийскому партнёрству (БЕП) и какие заделы междуна-

\footnotetext{
${ }^{1}$ Владимир Михайлович Шумилов, доктор юридических наук, профессор, заведующий кафедрой международного права Всероссийской академии внешней торговли Министерства экономического развития Российской Федерации, Заслуженный юрист Российской Федерации, г. Москва, Россия.

${ }^{2}$ Марианна Романовна Салия, кандидат юридических наук, старший преподаватель кафедры международного права Всероссийской академии внешней торговли Министерства экономического развития Российской Федерации, г. Москва, Россия.
}

(C) Шумилов В. М., Салия М. Р., 2021 
родно-правового регулирования этого движения остаются недостаточно использованными. Большое евразийское партнёрство рассматривается не только как обширная общая зона свободной торговли, где идёт либерализация (устранение) таможенных тарифов на товары взаимной торговли; это ещё и свободная инвестиционная зона, где должны устраняться барьеры на пути прямых инвестиций и инвесторов. Движение в сторону БЕП в АТР идёт пока, главным образом, на двустороннем уровне - за счёт вступления в соответствующее интеграционное объединение отдельных государств (т.е. путём расширения численного состава) и подписания с такими государствами соглашений о зонах свободной торговли. Показано, что главными международно-правовыми инструментами для сближения/сопряжения интеграционных блоков являются принцип наибольшего благоприятствования и исключения из него, а также принцип предоставления национального режима. В ходе региональной интеграции складываются новые международно-правовые договорные нормы и принципы, обычаи, целые институты международного права экономической интеграции, в частности «право ВРЭП», «право ТТП», «право АСЕАН» и т.д. Формируются будущие отрасли международного права, например, «международное социальное право», «международное цифровое право» и др. И в рамках ЕАЭС в целях сопряжения с другими интеграционными объединениями данное обстоятельство следует учитывать.

Ключевые слова: ЕАЭС, Всеобъемлющее евразийское партнёрство (ВЕП), Большое евразийское партнёрство (БЕП), Азиатско-Тихоокеанский регион (АТР), Всеобъемлющее региональное экономическое партнёрство (ВРЭП), Транстихоокеанское партнёрство (ТТП), АСЕАН, АТЭС, зона свободной торговли, свободная инвестиционная зона, международное право, право международной экономической интеграции, международное правосознание, принцип наибольшего благоприятствования, принцип предоставления национального режима.

Для циттирования: Шумилов В. М., Салия М. Р. Идея всеобъемлющего (большого) евразийского партнёрства в свете международного права (Часть 2) // Азиатско-Тихоокеанский регион: экономика, политика, право. 2021. №. 2. С. 111-123. https://doi.org/10.24866/1813-3274/2021-3/111-123. 
Original article

\title{
THE IDEA OF THE GREATER EURASIAN PARTNERSHIP IN THE LIGHT OF INTERNATIONAL LAW (Part 2)
}

\author{
V. M. Shumilov ${ }^{1}$, All-Russian Academy of Foreign Trade of the Ministry \\ of Economic Development of the Russian Federation, Moscow, Russia \\ E-mail: mezhdekpravo@gmail.com
}

\begin{abstract}
M. R. Saliya ${ }^{2}$, All-Russian Academy of Foreign Trade of the Ministry of Economic Development of the Russian Federation, Moscow, Russia E-mail: salimarianna@yandex.ru
\end{abstract}

Abstract. The essence of the idea of the "Greater Eurasian Partnership", announced in 2016, is to strengthen integration cooperation between the Eurasian Economic Union (EAEU) and the states of the Asia-Pacific region (APR), relevant international organizations and other integration associations in the region. As a result, a regional free trade zone and a free investment zone with the participation of the EAEU and the EAEU member states should be created. International treaties and soft law are the main regulators of this process, and the very direction of such integration is explained by the international legal consciousness and the ongoing restructuring of the modern international legal order. The article reveals what practical actions and regulatory tools are used by the EAEU to achieve the Greater Eurasian Partnership (BEP) and what reserves of international legal regulation of this movement remain insufficiently used. The Great Eurasian Partnership is considered not only as a broad common free trade area, where customs tariffs on mutual trade goods are liberalized (eliminated); it is also a free investment zone, where barriers to direct investment and investors should be removed. The movement towards the BEP in the Asia-Pacific region is still mainly at the bilateral level - due to the entry into the corresponding integration association of individual states (i.e. by expanding the number of members) and the signing of agreements on free trade zones with these states. It is shown that the main international legal instruments for the convergence/integration of integration blocks include the principle of most-favored nation and exclusion from it, as well as the principle of granting national treatment. In the course of regional integration, new international legal treaty norms and principles, customs, and entire institutions of in-

\footnotetext{
${ }^{1}$ Vladimir M. Shumilov, Doctor of Law, Professor, Head of the Department of International Law of the All-Russian Academy of Foreign Trade of the Ministry of Economic Development of the Russian Federation, Honored Lawyer of the Russian Federation, Moscow, Russia.

${ }^{2}$ Marianna R. Salia, Candidate of Law, Senior Lecturer, Department of International Law, All-Russian Academy of Foreign Trade, Ministry of Economic Development of the Russian Federation, Moscow, Russia.
} 
ternational law of economic integration are being formed. Future branches of international law are being formed - for example, "international social law", "international digital law", etc. And within the framework of the EAEU, in order to interface with other integration associations, this circumstance should be taken into account.

Keywords: EAEU, Comprehensive Eurasian Partnership, Greater Eurasian Partnership (GEP), Asia-Pacific Region (APR), Comprehensive Regional Economic Partnership (CREP), Trans-Pacific Partnership (TPP), ASEAN, APEC, free trade zone, free investment zone, international law, international economic integration law, international legal awareness, most-favored nation principle, national treatment principle.

For citing: Shumilov V. M., Salia M. R. The idea of the greater Eurasian partnership in the light of international law (Part 2) // PACIFIC RIM: Economics, Politics, Law. 2021. No. 3. C. 111-123. https://doi.org/10.24866/1813-3274/2021-3/111-123.

\section{Международно-правовой инструментарий сопряжения ЕАЭС и ТТП}

Создание Транстихоокеанского партнёрства (ТТП) было инициировано США [1]; практически все участвовавшие в нём государства являются членами АТЭС. Соглашение о Всеобъемлющем и прогрессивном Тихоокеанском партнёрстве было подписано в 2018 г. и состоит из 30 глав [2, с. 8]; оно охватило широчайший круг вопросов экономических взаимоотношений и, видимо, изначально задумывалось как большой шаг вперед по сравнению с вопросами, которые не удаётся продвинуть на переговорах в рамках ВТО. По сути дела, Соглашение о ТТП - это инструмент «обхода» действующего права ВТО: то, что не удаётся отрегулировать на глобальном уровне, перенесено на региональный уровень. В частности, в увязке с торгово-экономической проблематикой продвинуты институты, касающиеся стандартов защиты экологии, трудовых прав и перемещения рабочей силы, новых аспектов интеллектуальной собственности и цифровой среды, включая электронную торговлю; защиты потребителей и конкуренции; практически создан международно-правовой режим свободного инвестиционного пространства; выработаны единые правила по доступу бизнесменов на территорию друг друга; государства-участники вплотную развернуты в сторону гармонизации и унификации внутреннего права во многих сферах по нормам ТТП. Появился блок норм об особенностях защиты патентов на медицинские, биологические препараты; блок норм о борьбе с коррупцией. В рамках создания зоны свободной торговли планируется к 2030 г. устранить все пошлины. Под каждую крупную задачу созданы комитеты. Основным органом по Соглашению является Комиссия, состоящая из министров и старших должностных лиц и собирающаяся по согласованию со сторонами Соглашения (с переходящим председательством). Решения принимаются на основе консенсуса. 
В главе по экологическим вопросам содержатся статьи о борьбе с торговлей дикой фауной, незаконной вырубкой леса, незаконным рыболовством. Специальная глава отведена социально-экономической проблематике, что можно расценить как вклад в развитие «международного социального права», которое превращается в разветвлённую отрасль международного права. В неё вошли нормы о сокращении уровня бедности, развитии малого бизнеса, помощи женщинам, в том числе в доступе на рынок, развитии образования и науки, «процветания» народов.

В рамках Соглашения имеются специальные нормы, касающиеся развивающихся стран и наименее развитых стран, - таким образом дифференцируются международноправовые режимы для разных групп стран в зависимости от уровней развития.

В Соглашении закреплён порядок урегулирования споров между странамиучастницами по вопросам применения Соглашения. Если спор затрагивает нормы права ВТО, то коллегия при рассмотрении спора должна учитывать толкования и решения Апелляционного органа ОРС ВТО.

Не вошли в окончательный текст Соглашения положения, касающиеся валютных курсов: устранения манипуляций валютными курсами, отказа от девальвации в целях удешевления экспорта, а также положения о денежно-кредитной, а ещё шиpe - о макроэкономической политике. Переговоры по этим вопросам продолжаются. Впрочем, и без этого всем своим текстом Соглашение ведёт государства-члены к некоторой однородности экономик и их правового регулирования и к высокой степени вмешательства государства в экономику.

Понятно также, что для движения ЕАЭС в сторону Большого евразийского партнёрства необходимо будет учитывать международно-правовое содержание Соглашения о ТТП и «перенимать» многие институты «права ТТП», внедряя их в международно-правовой режим, существующий и развивающийся на основе Договора о ЕАЭС, а также в договорную практику ЕАЭС и государств-членов ЕАЭС с другими интеграционными образованиями и третьими странами.

\section{Международно-правовые аспекты взаимодействия ЕАЭС с прочими образованиями интеграционного типа}

Решение Высшего Евразийского экономического совета ЕАЭС (2019) об основных направлениях международной деятельности сделало акцент на выстраивании системного диалога, среди прочего, с Шанхайской организацией сотрудничества (ШОС), Ассоциацией государств Юго-Восточной Азии (АСЕАН), форумом «Азиатско-Тихоокеанское экономическое сотрудничество. Сам этот факт говорит о готовности ЕАЭС к развитию взаимосвязей с международными организациями и прочими образованиями интеграционного типа в АТР, а также о приоритетности этого направления. ЕАЭС намерен продолжать работу по выстраиванию Большого евразийского партнёрства путём, в частности, сближения с ШОС и АСЕАН [3, 
c. 105]. Ещё несколько лет назад в Стратегии развития ШОС (2015) было выражено намерение работать над проектом Соглашения между ЕАЭС и ШОС о Евразийском континентальном партнёрстве [4, с. 61].

ШОС была создана в 2001 г.; в её составе есть такие важные государства, как Россия, Китай, Индия, которые совместно составили некое политико-экономическое ядро ШОС. Основополагающим документом ШОС является Хартия 2002 г., которая декларирует нацеленность на содействие построению нового международного экономического порядка (ст. 1). Программой многостороннего торговоэкономического (2003), подписанной главами правительств, предусматривается создание зоны свободной торговли в ШОС.

В Договоре о долгосрочном добрососедстве, дружбе и сотрудничестве государств-членов Шанхайской организации сотрудничества (2007) подчёркивается опора на общепризнанные принципы и нормы международного права, Устав ООН и Хартию ШОС (ст. 1, 2); закреплено обязательство создавать благоприятные условия для развития торговли, стимулирования инвестиций и обмена технологиями (ст. 13); содействовать экономической деятельности на своей территории физических и юридических лиц, ведущих законную хозяйственную деятельность; обмениваться информацией о действующих и издаваемых законах; сотрудничать в разработке международно-правовых документов (ст. 16). Организовано в ШОС и взаимодействие на предпринимательском уровне: создан Деловой совет из представителей бизнеса и бизнес-ассоциаций.

Кроме того, в рамках ШОС подписано множество меморандумов, деклараций и прочих актов мягкого права, которые также создают необходимый нормативный фон для развития «права ШОС». Примерами могут служить меморандумы о взаимопонимании между ШОС и АСЕАН, СНГ, ЕврАзЭс - организацией-предшественницей ЕАЭС и др. (2005-2007).

Всей указанной совокупностью документов ЕАЭС оказался наиболее связанным содержанием и заложенным в акты правосознанием с ШОС, ОПОП, АСЕАН [5, с. 51] - теми структурами и проектами, с которыми возможно создать БЕП. Взаимодействие ЕАЭС и ШОС является иллюстративным примером сосуществования цивилизаций и общих устремлений; обе эти организации вместе формируют более устойчивую связь между Азией и Европой.

Ассоциация государств Юго-Восточной Азии (АСЕАН) - межправительственная организация десяти стран региона, образованная в 1967 г. с подписанием «Бангкокской декларации». Договорное оформление АСЕАН произошло в 1976 г. с подписанием «Балийской декларации» и Договора о дружбе и сотрудничестве в Юго-Восточной Азии.

В последующем организация расширялась и расширяла предмет деятельности: был подписан Договор об общем преференциальном тарифе (1992), имея в виду движение в сторону зоны свободной торговли; позднее подписан Устав АСЕАН 
(2007), согласно которому организация получила статус международного юридического лица.

В АСЕАН действуют: Соглашение о создании Зоны свободной торговли АФТА, Рамочное соглашение об инвестиционной зоне АСЕАН, Всеобъемлющее соглашение об инвестициях (2009); Договоры о промышленных проектах (1980) и о промышленном интегрировании (1981); Договор о совместных промышленных предприятиях (1983); Рамочное соглашение об услугах (1995) [6, с. 10]. Идёт постепенное сближение с ВРЭП, а также работа на двустороннем уровне: подписаны соглашения АСЕАН о зонах свободной торговли с Китаем, Японией, Республикой Корея, Индией и др. Сингапур, член АСЕАН, заключил договор о зоне свободной торговли с ЕАЭС (2019).

Правовой режим комплексной инвестиционной зоны предусматривает: либерализацию условий для инвестиций в странах АCEAH; защиту инвесторов из всех странучастниц; введение правил и норм регулирования, обеспечивающих транспарентность и предсказуемость процесса инвестирования; открытие для прямых инвестиций новых секторов экономики; подписание новых соглашений об избежании двойного налогообложения; зафиксированы и некоторые ограничения для инвестиций в отдельные сектора (например, рыболовство, сельское хозяйство) по каждой стране, но на временной основе. Важно, чтобы ЕАЭС подключился к этой инвестиционной зоне АСЕАН, и это укрепило бы интеграцию двух блоков как будущей - инвестиционной - части БЕП.

В 2015 г. государства-члены АСЕАН подписали соглашение об Экономическом Сообществе АСЕАН, которое ведёт к глубокой интеграции и созданию Единого экономического пространства.

Россия, будучи «партнёром по диалогу» с АCЕАН, активно продвигает идею сближения ЕАЭС с АСЕАН, создания общей зоны свободной торговли. В рамках АСЕАН регулярно проводятся встречи руководителей задействованных государств-членов, согласовываются планы действий. На встрече в 2016 г. была озвучена российская инициатива о формировании Экономического партнёрства по взаимосвязанности ЕАЭС, ШОС и АСЕАН. Есть понимание, что всеобъемлющая зона свободной торговли между ЕАЭС и АСЕАН нужна; создание такой зоны становится реальной перспективой [7].

В своё время между Россией и АСЕАН были подписаны несколько деклараций и программ, в том числе декларация о «развитом и всеобъемлющем партнёрстве» (2005), а также межправительственное Соглашение о сотрудничестве России и АСЕАН в области экономики и развития (2005), подчеркнувшее, среди прочего, цель поддержки региональной интеграции и определившее области, направления и формы взаимодействия. Россия присоединилась к Договору 1976 г. Создана необходимая организационная инфраструктура. Налажены контакты по линии торговопромышленных палат, имеется Деловой совет Россия - АСЕАН. Открыто Постоян- 
ное представительство России при АСЕАН. Президент РФ также подчеркивал важность углубления сотрудничества с АСЕАН для продвижения инициативы БЕП.

Между Евразийской экономической комиссией (ЕЭК) и АСЕАН был подписан Меморандум о взаимопонимании (2018), являющийся актом мягкого права. В нём стороны наметили направления взаимодействия: таможенное регулирование и упрощение процедур торговли, санитарные и фитосанитарные меры, техническое регулирование, электронная торговля, торговля услугами и инвестиции, развитие предпринимательства и др. (ст. 2).

Вместе с тем, проблемой в отношениях между двумя интеграционными блоками остаётся сложившаяся номенклатура торговли: из России поставляются в основном сырьевые товары, а в Россию - продукция высокотехнологичного машиностроения [8, с. 67]. Мешает развитию отношений недостаток нормативной институциональной основы сотрудничества: более бюрократические процедуры принятия решения в ЕАЭС и раздробленность правовой компетенции внутри Союза, поскольку ЕЭК может вести переговоры с внешними партнёрами по вопросам торговли, но не может по вопросам торговли услугами и инвестиций. Нет эффективных связей между предприятиями двух объединений - не выстроены товаропроводящие цепочки на уровне бизнеса. ЕАЭС и АСЕАН на данном этапе ограничиваются проектами узкой группы госкорпораций и госкомпаний, работающих в основном в сфере внешней торговли, энергетики и военно-технического сотрудничества.

Ещё одним образованием интеграционного типа в АТР является Форум АзиатскоТихоокеанского экономического сотрудничества (АТЭС), члены которого в основном расположены у береговой линии Тихого океана. Форум, образованный в 1989 г., не является полноправной международной организацией, международным юридическим лицом, у него нет устава. Это, скорее, «мягкая организация», «параорганизация». В АТЭС используется термин «участвующие экономики», а не термин «государстваучастники», «государства-члены»; в АТЭС участвуют Китай и с его одобрения Тайвань и Гонконг; всего - 21 «экономика». В 1998 г. в АТЭС была принята Россия.

В остальном АТЭС напоминает интеграционные объединения (организации): в его рамках созываются регулярные встречи (саммиты) лидеров государств/экономик, совещания на уровне министров, принимаются декларации, созданы комитеты, рабочие группы, секретариат, Деловой консультативный совет. Предметом деятельности и актов АТЭС названы: борьба с международным терроризмом, обеспечение безопасности в различных сферах, создание системы открытой и свободной торговли, либерального инвестиционного режима. Принимаются решения, касающиеся: поддержки многосторонней торговой системы и реформы ВТО; создания Азиатско-Тихоокеанской зоны свободной торговли; обеспечения устойчивого роста; раскрытия потенциала цифровой экономики; усиления гуманитарной взаимосвязанности экономик; стимулирования участия малых и средних 
предприятий, женщин, молодежи в региональной и глобальной экономике; проведение структурных реформ [2, с. 8]. Отдельно выделяются такие аспекты, как применение в одностороннем и многостороннем порядке - в интересах устойчивого развития экономик - денежно-кредитных, бюджетно-финансовых инструментов, регулирование обменного курса национальных валют, воздержание от девальвации и манипулирования обменными курсами для искусственного повышения конкурентоспособности экономик.

Либерализация тарифных и нетарифных барьеров в АТЭС носит добровольный характер: каждое государство-участник самостоятельно, в одностороннем порядке и без требований о встречных возмещениях, снижает ставки таможенных пошлин на те или иные товары - в этом уникальность регулирования в зоне. Соблюдаются преференции в пользу развивающихся стран на основе права ВТО, и в целом право ВТО является основой для взаимоотношений АТЭС и государствчленов АТЭС с другими интеграционными объединениями и государствамичленами таких объединений. А это означает, что в качестве главного принципа механизма для функционирования всех задействованных зон выступает принцип наибольшего благоприятствования, при соблюдении исключений из него (в частности и прежде всего исключения для международно-правового режима соответствующего интеграционного объединения).

Сотрудничество стран АТЭС между собой и с третьими странами АТР строится на межгосударственных соглашениях: их подписано около 60-ти, и ещё более 100 соглашений находятся в процессе переговоров. Имеется практика использования норм и принципов обычного права и «мягкого» права. Посредством «мягкого» права, в частности, регулируется ряд вопросов, касающихся экономических взаимоотношений Китая с Гонконгом (Сянганом) и Тайванем.

Таким образом, перспективы сближения ЕАЭС и АТЭС, ни с реальной - экономической, ни с международно-правовой точки зрения, пока не просматриваются. Наиболее возможный вариант - сопряжение с АТЭС Большого евразийского партнёрства, когда и если удастся его создать.

Наряду с ШОС, АСЕАН, АТЭС, Евразийский экономический союз активно ищет пути укрепления экономических взаимосвязей с другими образованиями, интеграционными блоками, а также организациями и параорганизациями, в деятельности которых прослеживается интеграционная составляющая, - с СНГ, БРИКС, ЕС и т.д. Практически по всем направлениям взаимодействия обсуждается проблематика цифровой экономики, электронной торговли, создания цифрового пространства.

Примером может служить Меморандум об углублении взаимодействия между Евразийской экономической комиссией и Исполнительным комитетом СНГ (2018), в котором стороны определили направления сотрудничества. Среди них и вопросы, входящие в сферу регулирования посредством права ВТО (санитарные правила, 
маркировка товаров, защита прав потребителей, государственные закупки и др.), и вопросы, которые идут дальше права ВТО: цифровая экономика, сотрудничество в сфере налоговой политики и администрирования, конкурентная политика, антимонопольное регулирование (п. 2).

\section{Заключение}

Таким образом, создание БЕП путём сопряжения ЕАЭС с ОПОП и ВРЭП, при усилении взаимодействия с другими образованиями интеграционного типа в АТР, вполне реальная задача. Международно-правовой инструментарий является главным и определяющим для её выполнения. Дорогу договорным международно-правовым нормам целенаправленно прокладывают акты мягкого права, и это средство сближения можно использовать активнее по разнообразным случаям и направлениям. Путь создания БЕП потребует существенного изменения внутреннего права, его адаптации к требованиям, которые согласовываются внутри партнёрств.

БЕП видится не только как обширная общая зона свободной торговли, где идёт либерализация (устранение) таможенных тарифов на товары взаимной торговли; это ещё и свободная инвестиционная зона, где должны устраняться барьеры на пути прямых инвестиций и инвесторов. Создаётся впечатление, что нацеленность именно на общее свободное инвестиционное пространство занимает у ЕАЭС вторичное место. Если у ЕАЭС не хватает полномочий, компетенции для того, чтобы вести переговоры с третьими странами по вопросам торговли услугами и создания свободных инвестиционных зон, следует постепенно - в том числе и через мягкое право внутри самого Союза - создавать условия для получения таких полномочий от государств-членов.

Движение в сторону БЕП в АТР идёт пока, главным образом, на двустороннем уровне - за счёт вступления в соответствующее интеграционное объединение отдельных государств (т.е. путём расширения численного состава) и подписания с такими государствами соглашений о зонах свободной торговли.

Усиление взаимосвязей между самими интеграционными объединениями через отдельные соглашения и мягкое право - следующий этап и ещё одно направление интеграции в АТР.

Центральное место в управлении интеграционными процессами в АТР, с международно-правовой точки зрения, занимают два принципа: принцип наибольшего благоприятствования и принцип предоставления национального режима - как они действуют на глобальном уровне согласно праву ВТО. При этом для сопряжения одного интеграционного объединения с другим необходимо «обойти» или отказаться от исключения, которое заложено в ПНБ в пользу «своего» интеграционного объединения, - именно это исключение не дает возможности объединить зоны двух интеграционных блоков. Роль своеобразного «исключения из исключения» может 
играть договорное обязательство между интеграционными блоками взаимно предоставить режим наибольшего благоприятствования; в таком случае государствачлены одного блока смогут получать либерализованные условия в торговой и инвестиционной сферах другого блока - так и произойдёт «слияние» соответствующих зон, расширение интеграционного пространства на основе единого международноправового режима. Принцип предоставления национального режима придаст дополнительную необходимую устойчивость и унификацию международноправовому режиму в общей свободной инвестиционной зоне.

Однако помимо таких форм «сопряжения», как создание зон свободной торговли и свободных инвестиционных зон, возможно «сопряжение» между блоками другим способом (и это видно по примеру «сопряжения» ЕАЭС и ОПОП): путём сближения в сотрудничестве по отдельным проектам на основе права ВТО и, как следствие, на основе ПНБ и принципа взаимного предоставления национального режима - как они понимаются и применяются в праве ВТО, при сохранении правомерных исключений из этих принципов.

В рамках региональной интеграции, создания зон свободной торговли и свободных инвестиционных зон государства АТР идут дальше норм, проистекающих из права ВТО; в предмет своих соглашений они включают новые вопросы, которые не входят в юрисдикцию ВТО, - так расширяется диапазон экономического сотрудничества и обходятся тупики, с которыми государства столкнулись на переговорах Дохийского раунда в ВТО, устанавливается новый международный экономический правопорядок.

В ходе региональной интеграции складываются новые международноправовые договорные нормы и принципы, обычаи, целые институты международного права экономической интеграции, в частности «право ВРЭП», «право ТТП», «право АСЕАН» и т.д. Формируются будущие отрасли международного права, например, «международное социальное право», «международное цифровое право» и др. И в рамках ЕАЭС в целях сопряжения с другими интеграционными объединениями данное обстоятельство следует учитывать.

Вместе с тем, ряд перспективных вопросов, даже в уже подписанных соглашениях о партнёрстве, не предусмотрен, - в частности, вопрос о Международном инвестиционном суде. Возможно, ЕАЭС мог бы сыграть в таких вопросах некую стимулирующую, опережающую роль, инициировав создание Международного инвестиционного суда на «своём» интеграционном пространстве и продвигая его модель в БЕП.

Понятно также, что для движения ЕАЭС в сторону Большого евразийского партнёрства необходимо будет учитывать международно-правовое содержание Соглашения о ТТП и «перенимать» многие институты «права ТТП», внедряя их в международно-правовой режим, существующий и развивающийся на основе Дого- 
вора о ЕАЭС, а также в договорную практику ЕАЭС и государств-членов ЕАЭС с другими интеграционными образованиями и третьими странами.

В итоге все мероприятия по созданию правового режима внутри партнёрств ведут к расширению государственного вмешательства в экономику через право, регулирование многообразных сфер отношений. А требование к государствам-участникам ТТП сокращать поддержку государственных предприятий (читай: субсидирование, гарантированные закупки, государственные инвестиции и т.п.) тоже ведёт к этому же.

Нет сомнений, что БЕП - не просто общее интеграционное пространство, созданное на основе договорного объединения автономных зон свободной торговли и свободных инвестиционных зон, с активным «вторжением» в регулирование социальной сферы. БЕП - это один из центров экономической силы в новом многополярном мироустройстве, способ мирного сосуществования разных цивилизационных пространств. Стремление к построению БЕП свидетельствует, что международное правосознание дозрело до «интеграции интеграций» - создания «суперпартнёрств» с зонами свободной торговли и свободными инвестиционными зонами, в которых стороны в большей степени опираются на равенство суверенитетов [9] и общепризнанные принципы международного права.

\section{Список литературы}

1. Агеев, А. И. Большое евразийское партнёрство: проект, встречный Транстихоокеанскому партнёрству / А. И. Агеев, С. И. Борталевич, Е. Л. Логинов // Экономические стратегии. - 2016. - № 6. - С. 20-31.

2. Томилов, М. В. Перспективы углубления торговой интеграции в рамках современных торгово-экономических объединений АТР // Власть и управление на Востоке России. - 2019. - № 2. - С. 8-21.

3. Лузянин, С. Г. Сотрудничество России и Китая в ШОС по реализации концепции Большого евразийского партнёрства / С. Г. Лузянин, А. Ф. Клименко // Китай в мировой и региональной политике. История и современность. - 2019. Т. 24, № 24. - С. 98-113.

4. Петрова, Г. В. Стратегическое партнёрство ЕАЭС и ШОС 2016-2025 гг. // Международное сотрудничество евразийских государств: политика, экономика, право. - 2016. - № 4. - С. 61-70.

5. Степанов, Н. С. ШОС и ЕАЭС как основа будущего Большого евразийского партнерства / Н. С. Степанов, Е. А. Соколовская // Дискуссия. - 2018. - № 4 (89). C. 46-55.

6. Саидмухторов, А. Б. Экономическое сотрудничество государств в рамках ACEАН: международно-правовые аспекты : автореф. дис. ... канд. юрид. наук / Ф. Б. Саидмухторов ; РУДН. - Москва, 2021. - 26 с. 
7. Хейфец, Б. А. Перспективы создания зоны свободной торговли между ЕАЭС и АСЕАН // Вестник Института экономики РАН. - 2018. - № 5. - С. 107-120.

8. Канаев, Е. ЕАЭС и АСЕАН: результаты и перспективы сотрудничества / Е. Канаев, А. Королев // Мировая экономика и международные отношения. 2020. - Т. 64, № 1. - С. 64-72.

9. Зорькин, В. Верховенство права и императив безопасности // Российская газета. $-2012 .-16$ мая.

\section{References}

1. Ageev A. I., Bortalevich S. I., Loginov E. L. Bol'shoe evraziiskoe partnerstvo: proekt, vstrechnyi Transtikhookeanskomu partnerstvu [The Great Eurasian Partnership: a project meeting the Trans-Pacific Partnership]. Ekonomicheskie strategii, 2016, no. 6, pp. 20-31.

2. Tomilov M. V. Perspektivy uglubleniya torgovoi integratsii v ramkakh sovremennykh torgovo-ekonomicheskikh ob"edinenii ATR [Prospects for deepening trade integration in the framework of modern trade and economic associations of the APR]. Vlast' $i$ upravlenie na Vostoke Rossii, 2019, no. 2, pp. 8-21.

3. Luzyanin S. G., Klimenko A. F. Sotrudnichestvo Rossii i Kitaya v ShOS po realizatsii kontseptsii Bol'shogo evraziiskogo partnerstva [Cooperation between Russia and China in the SCO to implement the concept of the Greater Eurasian Partnership]. Kitai $v$ mirovoi i regional'noi politike. Istoriya i sovremennost', 2019, vol. 24, no. 24, pp. 98-113.

4. Petrova G. V. Strategicheskoe partnerstvo EAES i ShOS 2016-2025 gg. [Strategic partnership between the EAEU and the SCO 2016-2025]. Mezhdunarodnoe sotrudnichestvo evraziiskikh gosudarstv: politika, ekonomika, pravo, 2016, no. 4, pp. 61-70.

5. Stepanov N. S., Sokolovskaya E. A. ShOS i EAES kak osnova budushchego Bol'shogo evraziiskogo partnerstva [SCO and EAEU as the basis of the future Greater Eurasian partnership]. Diskussiya, 2018, no. 4 (89), pp. 46-55.

6. Saidmukhtorov A. B. Ekonomicheskoe sotrudnichestvo gosudarstv v ramkakh ASEAN: mezhdunarodno-pravovye aspekty [Economic cooperation of states within ASEAN: international legal aspects]. Cand. Dis. (Legal. Sci.). Synopsis. Moscow, 2021. 26 p.

7. Kheifets B. A. Perspektivy sozdaniya zony svobodnoi torgovli mezhdu EAES i ASEAN [Prospects for the creation of a free trade zone between the EAEU and ASEAN]. Vestnik Instituta ekonomiki RAN, 2018, no. 5, pp. 107-120.

8. Kanaev E., Korolev A. EAES i ASEAN: rezul'taty i perspektivy sotrudnichestva [EAEU and ASEAN: results and prospects of cooperation]. Mirovaya ekonomika $i$ mezhdunarodnye otnosheniya, 2020, vol. 64, no. 1, vol. 64, no. 1, pp. 64-72.

9. Zorkin V. Verkhovenstvo prava i imperativ bezopasnosti [Rule of law and the imperative of security]. Rossiyskaya Gazeta, 2012, May 16. 